\title{
SCIENTIFIC REP

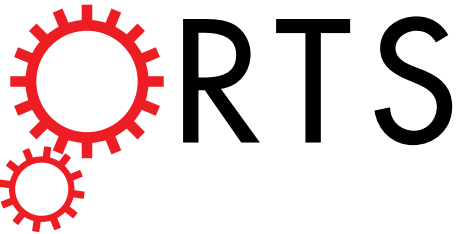 \\ OPEN \\ Deciphering the evolution of birdwing butterflies 150 years after Alfred Russel Wallace
}

Received: 02 April 2015

Accepted: 29 May 2015

Published: 02 July 2015

\author{
Fabien L. Condamine ${ }^{1}$, Emmanuel F. A. Toussaint ${ }^{2}$, Anne-Laure Clamens ${ }^{3}$, \\ Gwenaelle Genson ${ }^{3}$, Felix A. H. Sperling ${ }^{1,+}$ \& Gael J. Kergoat ${ }^{3,+}$
}

One hundred and fifty years after Alfred Wallace studied the geographical variation and species diversity of butterflies in the Indomalayan-Australasian Archipelago, the processes responsible for their biogeographical pattern remain equivocal. We analysed the macroevolutionary mechanisms accounting for the temporal and geographical diversification of the charismatic birdwing butterflies (Papilionidae), a major focus of Wallace's pioneering work. Bayesian phylogenetics and dating analyses of the birdwings were conducted using mitochondrial and nuclear genes. The combination of maximum likelihood analyses to estimate biogeographical history and diversification rates reveals that diversity-dependence processes drove the radiation of birdwings, and that speciation was often associated with founder-events colonizing new islands, especially in Wallacea. Palaeo-environment diversification models also suggest that high extinction rates occurred during periods of elevated sea level and global warming. We demonstrated a pattern of spatio-temporal habitat dynamics that continuously created or erased habitats suitable for birdwing biodiversity. Since birdwings were extinction-prone during the Miocene (warmer temperatures and elevated sea levels), the cooling period after the mid-Miocene climatic optimum fostered birdwing diversification due to the release of extinction. This also suggests that current global changes may represent a serious conservation threat to this flagship group.

"[...] for the purpose of investigating the phenomena of geographical distribution and of local or general variation, [...] several groups differ greatly in their value and importance. [...] Preeminent among such groups are the diurnal Lepidoptera or Butterflies, whose extreme beauty and endless diversity have led to their having been assiduously collected in all parts of the world [...]" Alfred Russel Wallace'.

Situated between the Indian and Pacific Oceans, the region hereafter referred to as the Indomalayan-Australasian Archipelago (IAA) represents the largest and arguably most complex assemblage of islands in the world, housing a substantial proportion of Earth's biodiversity ${ }^{2,3}$. In its heart lie 14 biodiversity hotspots delineated by sharp biogeographical boundaries ${ }^{2}$. One of the most prominent biogeographical barriers is Wallace's line, demarcating two biogeographical realms: the Asian (Sunda) and the Australian (Sahul) biota. In a seminal paper, Alfred Russel Wallace ${ }^{4}$ was the first to formalize the affinities of two distinct biotic regions separated by the deep Makassar Strait. He found that several communities of birds, mammals and insects were mainly restricted to one side of a narrow geographical area while fewer were found evenly on both sides ${ }^{4,5}$. Following Wallace's pioneering work, other biogeographical boundaries were proposed within the IAA, notably Lydekker's line, which follows the continental margin of the Australian Shelf ${ }^{6,7}$. Currently, the region lying between Wallace's and Lydekker's

${ }^{1}$ University of Alberta, Department of Biological Sciences, Edmonton, T6G 2E9, AB, Canada. ${ }^{2}$ SNSB-Bavarian State Collection of Zoology, Münchhausenstr 21, 81247 Munich, Germany. 3INRA, UMR 1062 Centre de Biologie pour la Gestion des Populations (INRA, IRD, CIRAD, Montpellier SupAgro), 755 avenue du campus Agropolis, 34988, Montferrier-sur-Lez, France. ${ }^{\dagger}$ These authors jointly supervised this work. Correspondence and requests for materials should be addressed to F.L.C. (email: fabien.condamine@gmail.com) 
lines, referred to as Wallacea, is acknowledged as a transitional biogeographical unit between the Asian and Australian biotas ${ }^{3}$. Interestingly, Wallace's line has also been shown to be more permeable to plants and insects, as their greater dispersal ability is thought to have allowed some species to colonize both sides of the line $\mathrm{e}^{8-12}$.

The dynamic geological and climatic history of the IAA generated a matrix of islands in which the distribution of land and sea has been altered extensively through time ${ }^{13}$, alternatively promoting or impeding diversification ${ }^{14}$. The progressive collision of the Sunda and Sahul shelves during the early Miocene engendered high volcanic activity that formed new islands on which diversification may have started $^{15}$. The assembly of Wallacea, especially Sulawesi in the mid-Miocene, may explain the origin and diversification of clades ${ }^{16}$, with Wallacea acting as a biogeographical crossroads between Sahul and Sunda biotas and/or as an evolutionary cradle of diversity (or species-pump) fostering rapid radiation with higher speciation rates. Repeated sea-level fluctuations ${ }^{17}$, promoting habitat alteration or formation, colonization of new niches and ultimately allopatric speciation, have acted as an important driver in the IAA $^{8,11,14}$. Clade characteristics that allow continual adaptation and diversification within a region may also govern the current species richness such that diversity-dependent processes and ecological or geographical carrying capacity confer some limits to diversification ${ }^{5,15}$, especially in the context of island biogeography ${ }^{4}$. To better tease apart the processes underlying the megadiversity observed in the IAA it is essential to account for the historical legacy of the region and the evolutionary history of groups found on each side of Wallace's line ${ }^{3}$.

One hundred and fifty years ago, Wallace ${ }^{1}$ published one of his most influential papers, in which he used butterflies of the family Papilionidae as a model system to describe and understand species richness across the entire IAA. He focused on the charismatic giant birdwings, a well-studied clade of large and brightly coloured butterflies comprising three extant genera and about 37 species distributed from India to Australia ${ }^{18}$, with numerous island endemics harbouring unique wing patterns (Supplementary Fig. S1). Birdwing species are iconic species for invertebrate conservation; several species are considered endangered and benefit from strict conservation policies. The Convention on International Trade in Endangered Species of Wild Fauna and Flora (CITES) has listed all species on annex II (except Ornithoptera alexandrae listed on the annex I). The International Union for the Conservation of Nature (IUCN) red list of threatened species recognizes eight threatened species belonging to Ornithoptera (although O. paradisea is listed as Lower Risk/Least Concern), and three Troides species (T. andromache as Lower Risk/Near Threatened, T. dohertyi as Vulnerable, and T. prattorum as Vulnerable). The IUCN red list lists only three species (O. alexandrae, O. croesus and O. meridionalis) as Endangered.

Ever since Wallace ${ }^{1}$, birdwing butterflies have become a prime biological model to discriminate factors driving island speciation and distribution patterns in the IAA ${ }^{18-23}$. Their distinct biogeographical pattern across Wallacea makes them valuable for studying the geological assembly of the region and the ecological opportunities provided by emerging islands (Fig. 1). The genus Ornithoptera (14 species) is endemic to the Melanesian region, where species diversity peaks in New Guinea, although a few species are found on the other side of Lydekker's line (e.g. the Wallace's Golden Birdwing O. croesus in Halmahera). This genus includes the two largest extant species of butterfly, Queen Alexandra's Birdwing (O. alexandrae) and the Goliath Birdwing (O. goliath), which have a wingspan of up to 28 centimetres. The genus Trogonoptera (two species) is restricted to the west of Wallace's line, where T. brookiana occurs in the Greater Sunda Islands (Borneo, Sumatra, and Java) and T. trojana in Palawan. The genus Troides (21 species) has most of its species diversity in the Indomalayan region but presents an extensive distribution going northward to India (T. minos), eastward to the Philippines (T. rhadamantus) and has some species crossing through Lydekker's line into the Australian region (T. oblongomaculatus from Sulawesi to New Guinea). Birdwings are generally strong fliers ${ }^{1,19}$ and highly specialized on Aristolochiaceae $e^{18-20}$, which are usually toxic for herbivores ${ }^{24}$.

Despite his difficulties in disentangling species boundaries ${ }^{25}$, Wallace ${ }^{1}$ used estimates of species richness to hypothesize that the Greater Sunda Islands (especially Borneo) were the ancestral area of this clade from which it later dispersed towards Australia (a similar pattern has also been found in other clades $^{3}$ ). Wallace postulated that 'settling down' was a strong factor in island speciation (here referred to as founder-event speciation), especially for these good dispersers, and further argued that island features and environmental factors subsequently fostered morphological variation and eventually contributed to speciation (corresponding to the hypothesis of Wallacea acting as a species pump). Yet the main triggers responsible for the diversification of these emblematic butterflies remain equivocal.

Building on the pioneering work of Wallace, we revisit some of his conclusions. Here we rely on a dated phylogeny of a comprehensive sampling of birdwings to estimate what processes shaped their current biogeographical pattern, using novel approaches ${ }^{26,27}$. We also implement distinct sets of diversification analyses in order to: $(i)$ estimate the influence of Wallacea on birdwing speciation and extinction rates; (ii) test whether their species richness is still expanding today or has reached an equilibrium suggesting that birdwing diversification may have been influenced by diversity-dependent processes; and (iii) assess the impact of palaeo-environmental variables (temperature and sea level) on diversification rates.

\section{Results}

Phylogeny, species monophyly, and dating. Bayesian phylogenetic estimations yielded resolved trees indicating that all three genera and most species are monophyletic with high support (Supplementary 


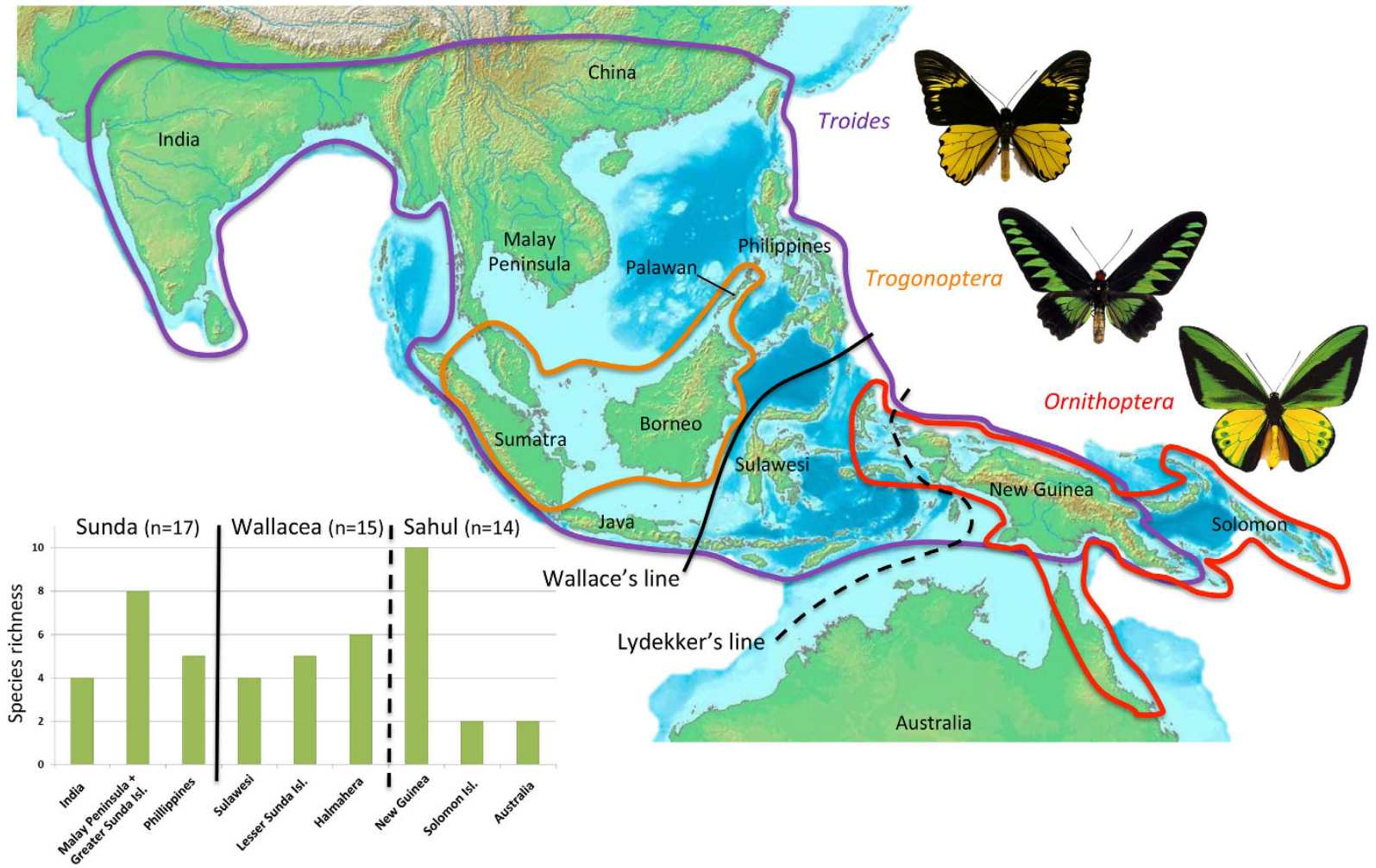

Figure 1. Distributional pattern of birdwing butterflies originally described by Wallace showing species richness west and east of Wallace's and Lydekker's lines, and in each important biogeographical unit of the Indomalayan-Australian Archipelago used here. Pictures of birdwing butterflies made by Fabien Condamine. Map drawn with PowerPoint by Fabien Condamine.

Text S1 and Supplementary Fig. S2). The only marked exception was Troides haliphron that was recovered as paraphyletic, suggesting that two molecular lineages with different evolutionary trajectories may be recognised (T. h. haliphron plus T. h. purabu occurring in South Sulawesi, and T. $h$. socrates plus T. h. naias in Sumbawa to Alor islands, Supplementary Fig. S2). This pattern was independently recovered using different molecular datasets and as a result we provisionally recognize two species within T. haliphron. The first putative haliphron species would include the subspecies in the Sulawesi region, i.e. T. h. haliphron (Southwest Sulawesi), T. h. purabu (Batuata Island), T. h. pistor (Bonerate, Jampea, Kalaotoa, and Madu islands), T. $h$. pallens (Selayar Island) and T. $h$. eleonorae (Buton Island). The second putative haliphron species would comprise the two subspecies T. $h$. naias and T. $h$. socrates, occurring in the Lesser Sunda Islands (Alor, Flores, Solor, Sumba, Sumbawa, and Wetar islands), and possibly T. $h$. bellwoni (Lucipara Islands, Moluccas).

We assembled a species-level dataset comprising 4,395 nucleotides (five genes) for 34 birdwing species and 31 outgroups that was used to conduct simultaneous inferences of species-level phylogenetics and divergence time estimates. The species-level phylogenetic tree yielded by the BEAST analysis was fully resolved and presented robust node supports (Fig. 2). We found that Trogonoptera was sister to the two other genera, and that the three subgenera within Ornithoptera (i.e. Aetheoptera, Ornithoptera, and Schoenbergia) were monophyletic, supporting previous morphological and molecular studies ${ }^{21-23}$. The phylogeny of Ornithoptera is highly congruent with the previous work of Morinaka et al. ${ }^{21}$, who only used the mitochondrial gene ND5. Despite some previous studies that lumped Ornithoptera, Troides and Trogonoptera into a single genus ${ }^{1,19}$, we follow the views of several recent authors that advocate maintaining the taxonomic rank of the three genera based on morphological, ecological and distributional data ${ }^{18,21,22,28}$. We inferred an origin of birdwings in the Oligocene around $25.8 \mathrm{Myr}$ ago (95\% HPD 22.2-29.9 Myr ago). Ornithoptera and Troides diverged in the early Miocene around 19.3 Myr ago (95\% HPD 16.3-22.8 Myr ago). Both genera diversified in the middle Miocene around 11.5 Myr ago (95\% HPD 8.4-15.3 Myr ago), and 13.6 Myr ago (95\% HPD 10.8-16.4 Myr ago), respectively. These results are independent of the speciation tree prior used (Supplementary Text S1).

Biogeography and diversification rates. Biogeographical maximum likelihood analyses (unconstrained by a stratified model) statistically supported models in which founder-event speciation was allowed (Supplementary Text S1). In all models, the founder-event parameter significantly improved the likelihood of biogeographical estimations $(\triangle \mathrm{AICc}>10$ for all pairs; see Supplementary Fig. S3 and 

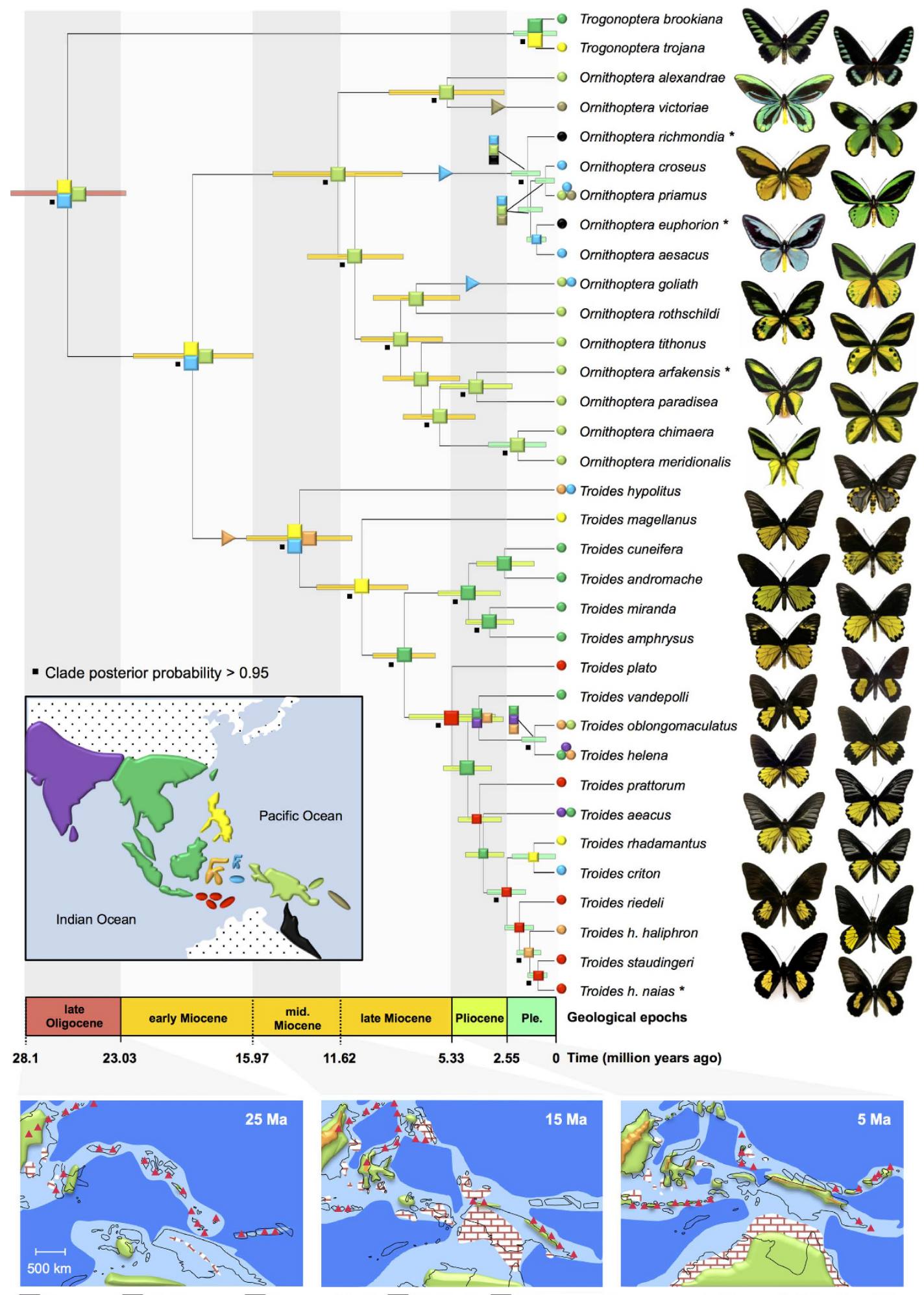

Deep sea $\square$ Shallow sea $\square$ Permanent land

Highland Calcareous plateaus exposed at times

$\Delta$ Volcanic activity

Figure 2. Dated Bayesian phylogeny of the birdwing butterflies radiation and palaeo-tectonic evolution of the Indomalayan-Australian Archipelago. Coloured squares on nodes indicate biogeographical location as in the inset map, with triangles indicating colonizations. A timescale is shown spanning the full evolutionary history of the group. Panels at the bottom include maps of the distribution of land and sea at respectively 25, 15 and $5 \mathrm{Myr}$ ago sensu $u^{13,15}$. The asterisk next to terminal taxon names indicates those not figured. Pictures of birdwing butterflies made by Fabien Condamine. Maps drawn with PowerPoint by Fabien Condamine using various sources (e.g. Ref. 13,15). 


\begin{tabular}{|c|c|c|c|c|c|}
\hline Type of birth-death & Methods used & References & Data used & Settings & Results \\
\hline $\begin{array}{l}\text { Trait-dependence } \\
\text { (rates vary as } \\
\text { a function of a } \\
\text { character state for } \\
\text { a trait) }\end{array}$ & GeoSSE (make.geosse) & Goldberg et al. ${ }^{44}$ & $\begin{array}{l}500 \text { posterior trees } \\
+ \text { geographical } \\
\text { occurrence } \\
\text { (Wallacea endemic, } \\
\text { endemic to the } \\
\text { remaining region, } \\
\text { or widespread } \\
\text { across the } \\
\text { archipelago) }\end{array}$ & $\begin{array}{l}12 \text { models to test } \\
\text { whether a character } \\
\text { state impacted } \\
\text { speciation and/ } \\
\text { or extinction and/ } \\
\text { or transition rates } \\
\text { between Wallacea } \\
\text { and the remainder }\end{array}$ & $\begin{array}{c}\text { Transition rate } \\
\text { out of Wallacea } \\
\text { is } 10 \text {-fold more } \\
\text { elevated than } \\
\text { transition rate } \\
\text { into Wallacea (no } \\
\text { effect of the trait } \\
\text { on diversification } \\
\text { rate) }\end{array}$ \\
\hline $\begin{array}{l}\text { Diversity-dependence } \\
\text { (rates vary as a } \\
\text { function of the } \\
\text { number of species) }\end{array}$ & $\mathrm{DDD}\left(d d \_M L\right)$ & Etienne et al. ${ }^{29}$ & $\begin{array}{l}\text { MCC tree of the } \\
\text { whole tree, and } \\
\text { MCC trees of } \\
\text { Ornithoptera and } \\
\text { Troides (to see if } \\
\text { they reach their } \\
\text { carrying capacity) }\end{array}$ & $\begin{array}{c}5 \text { models to test } \\
\text { whether speciation } \\
\text { declines with } \\
\text { diversity and/or } \\
\text { extinction increases } \\
\text { with diversity }\end{array}$ & $\begin{array}{c}\text { All clades } \\
\text { have reached } \\
\text { their carrying } \\
\text { capacities, } \\
\text { with extinction } \\
\text { increasing as } \\
\text { diversity increases }\end{array}$ \\
\hline $\begin{array}{l}\text { Environmental- } \\
\text { dependence (rates } \\
\text { vary as a time-variable } \\
\text { environment) }\end{array}$ & $\begin{array}{l}\text { Condamine et al.'s } \\
\text { approach }\end{array}$ & Condamine et al. ${ }^{46}$ & $\begin{array}{c}500 \text { posterior } \\
\text { trees }+ \text { past } \\
\text { temperatures }{ }^{47}+ \\
\text { past sea levels }{ }^{17}\end{array}$ & $\begin{array}{c}6 \text { models ( } 3 \text { for } \\
\text { each environmental } \\
\text { variable) to test } \\
\text { whether rates vary } \\
\text { or not (exponential } \\
\text { variation) }\end{array}$ & $\begin{array}{l}\text { Extinction rate } \\
\text { is positively } \\
\text { associated with } \\
\text { warm climate and } \\
\text { elevated sea level }\end{array}$ \\
\hline
\end{tabular}

Table 1. Summary of the analyses of diversification that highlights the main results. Notes: $\mathrm{MCC}=$ maximum clade credibility.

Supplementary Table S1). The biogeographical estimations with the best model (DEC+J) is presented in Fig. 2, indicating that the birdwing ancestor originated in the vicinity of proto-Halmahera, New Guinea and the Philippines. The results of diversification rate analyses are summarized in Table 1 . We found that a growing species diversity that progressively reached diversity equilibrium influenced the overall rates of birdwings diversification. Diversity-dependence models estimated a carrying capacity similar to the current species richness of the clade (this pattern is also recovered for Ornithoptera and Troides, analysed separately, Supplementary Table S2 and Supplementary Fig. S4). A diversity-dependent extinction model was recovered as the best best-fitting diversity-dependence model ( $\triangle \mathrm{AICc}$ ranged between 2.5 and 17), despite having received little empirical support in other comparable studies ${ }^{29}$. We found that Wallacea did not promote speciation rates but rather triggered dispersal (increased transition rates) towards other areas, as the best-fitting GeoSSE model was one in which only transition rates varied and both speciation and extinction remained equal among the two areas ( $\triangle \mathrm{AICc}$ ranged between 2.2 and 8.4, Supplementary Table S3). Transition rates (or dispersal rates in this context) were estimated to be 10 -fold higher from Wallacea towards the remaining areas, compared to the other direction, suggesting an important role of Wallacea as a biogeographical crossroads rather than a species pump (Supplementary Fig. S5).

Analyses of diversification rates as a function of palaeo-environment suggested that past sea level and temperature fluctuations better explained diversification within birdwings (Fig. 3). The analyses indicated that temperature and sea-level changes have had similar impacts on the diversification of birdwing butterflies ( $\triangle \mathrm{AICc}$ ranged between 1.9 and 2.6, Supplementary Table S4). Models testing the influence of past sea-level fluctuations suggested that the best-fitting model had a constant speciation rate (not affected by sea-level fluctuations) while extinction was positively correlated to past sea-level fluctuations such that higher sea level generated higher extinction, and vice versa (Fig. 3 ). The models built to assess the impact of palaeo-temperature fluctuations showed that the best fitting model is the one in which speciation remained constant (and was not affected by temperature fluctuations) whereas extinction was positively linked to past changes in temperature such that elevated temperature increased the extinction rate, and vice versa (Fig. 3).

We keep in mind that the data do not distinguish strongly between the models, especially for the palaeo-environment models. The $\triangle \mathrm{AICc}$ and Akaike weights are in the category 'barely worth mentioning' according to commonly-used scales, but models where $\triangle \mathrm{AICc}$ is in the $2-7$ range have some support and should rarely be dismissed. It is interesting that the tests for an effect of the palaeo-environment provide some support to models with varying extinction, although this cannot be considered a very confident conclusion given the available phylogenetic data.

\section{Discussion}

The hypothesis of Wallacea acting as a species pump, in which in situ-speciation triggers diversification, has rarely been tested. Yet, Wallacea is recognized as a major evolutionary arena for biodiversity ${ }^{16}$. Wallace $^{1}$ proposed that Sulawesi was a keystone of butterfly evolution because it contains a remarkable diversity of endemics ${ }^{30}$ and stands upon the dividing line between two biogeographical regions. Our dating analyses indicate that birdwing butterfly speciation on Wallacea did not occur before the Miocene, which is consistent with geological evidence ${ }^{13}$. The timeframe of Sulawesi colonization by birdwing butterflies (mid-Miocene) and speciation on the island (mid-Miocene/Pliocene) is also fully compatible with data presented in a meta-analysis of this island ${ }^{16}$. However, our data and analyses do not support the 
a) Past global climate change

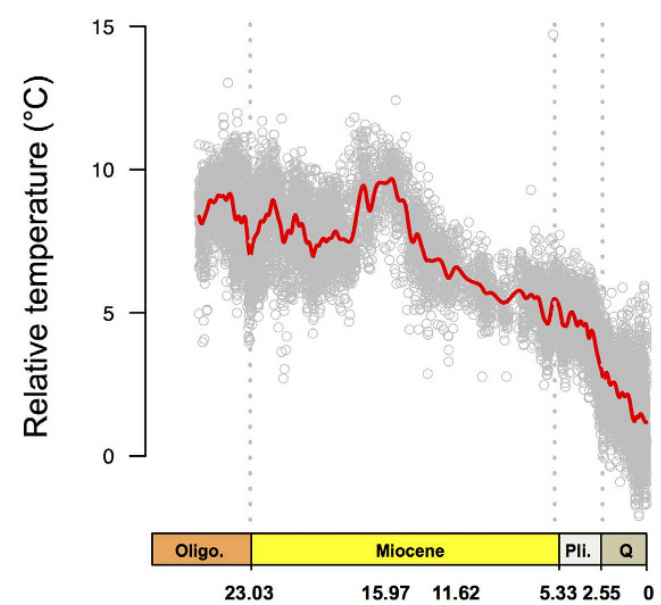

c) Warming climate increased extinction

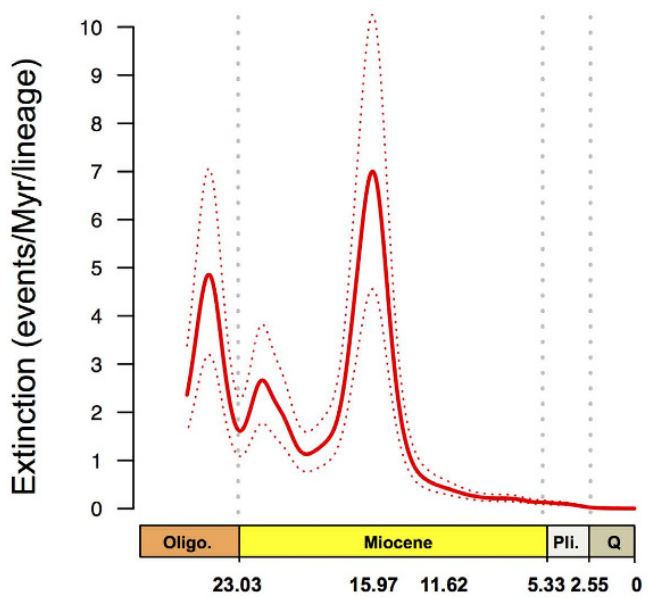

b) Past fluctuations of sea level

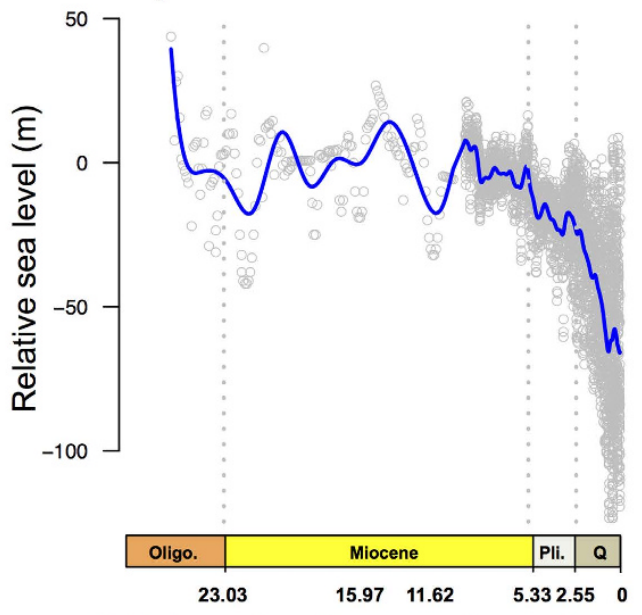

d) High sea level increased extinction

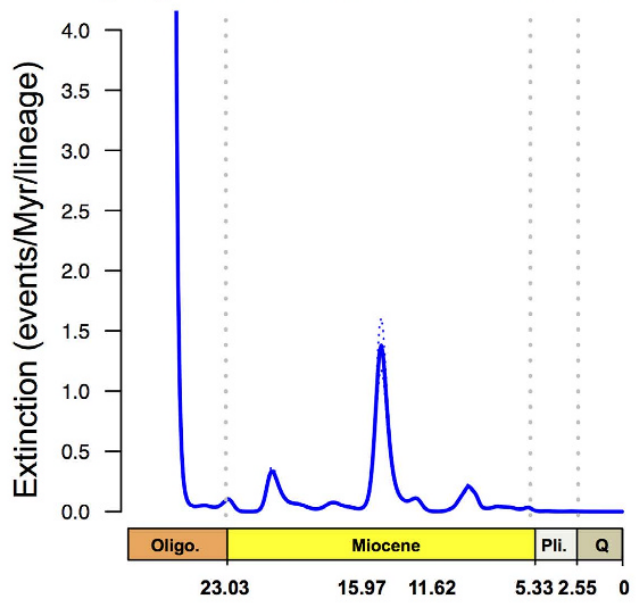

e) Change of land area under sea-level variations

Current coastlines

Land extensions by lower sea level:

When sea level is $-65 \mathrm{~m}$ below

When sea level is $-110 \mathrm{~m}$ below

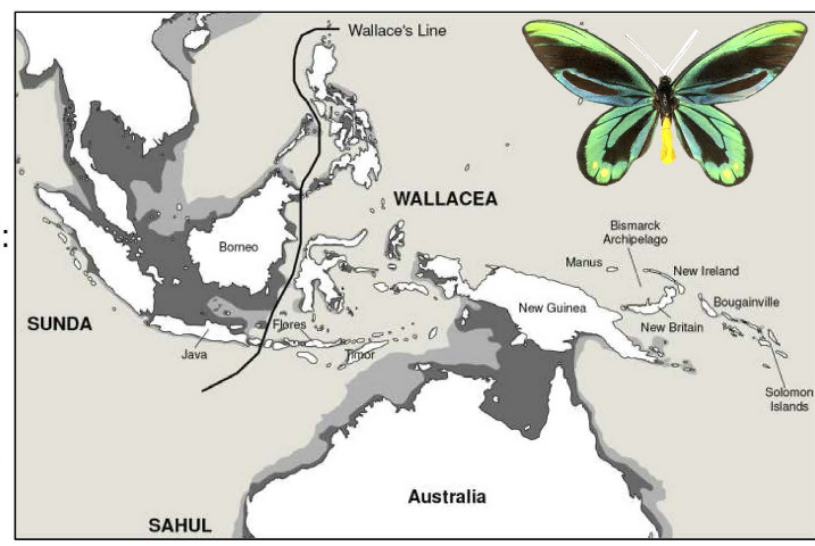

Figure 3. Evaluation of the effect of environmental changes on diversification processes in the evolutionary history of birdwing butterflies. (a) Major trends in global climate change ${ }^{46}$, and (b) major trends in global sea level ${ }^{17}$ during the last $26 \mathrm{Myr}$, estimated from relative proportions of different oxygen isotopes. (c) Best model for temperature-dependent diversification with a positive relationship between extinction rate and palaeo-temperatures. (d) Best model for a sea level-dependent diversification with a positive relationship between extinction rate and past sea levels. Dotted lines indicate the maximum and minimum limits of the confidence interval obtained from 500 phylogenies, and the continuous line represents the average. (e) The Indomalayan-Australasian Archipelago when sea level varied in the past, and under two projections of sea-level decrease. Pictured is Ornithoptera alexandrae, a threatened species living in the coastlines of Southeast Papua New Guinea. Oligo., Oligocene; Pli., Pliocene; and Q, Quaternary. Picture of the birdwing butterfly made by Fabien Condamine. Map drawn with PowerPoint by Fabien Condamine. 
role of Wallacea as a trigger for speciation because no difference in speciation and extinction rates was recovered by our diversification analyses. Both biogeographical and diversification analyses instead suggest that Wallacea was the source of numerous dispersal events towards neighbouring areas (Sahul and Sunda). In this context, the Pliocene onset of periodic sea-level changes may have played an important role by increasing dispersal from Sulawesi during periods of low sea level or by increasing the isolation of species/populations, and therefore facilitating allopatric speciation during periods of elevated sea level. Altogether, these results support Wallace's view on the role of Wallacea as a biogeographical pathway for butterflies, although these biogeographical events did not impact birdwing diversification rates per se.

Although Wallace did not provide a formal hypothesis for the origin of birdwing butterflies, our biogeographical estimations tend to support the hypothesis of a complex ancestral origin lying between the Philippines, the Moluccas and New Guinea. The complexity of the geological history of the IAA region makes it difficult to reliably know the past distribution of land and sea at a given point in time ${ }^{13,15}$. Prior to $25 \mathrm{Myr}$ some palaeo-islands, or terranes, were possibly aerial at that time and may have harboured the birdwing ancestor (see the inset maps in Fig. 2). The Moluccas and New Guinea, to some extent, share a common geological origin as part of the Australian Plate whereas some islands of the Philippines and the northernmost part of New Guinea are of oceanic origin, but all from the same geographical area $^{13}$. We suggest that an occurrence of the birdwing butterfly ancestor on a proto-Papuan arc stretching from the westernmost part of the Sula Spur to central New Guinea is a scenario consistent with "island hopping", in which ancient islands provided discrete temporal and spatial context for colonization and speciation and greatly extend the temporal window theoretically available for insular evolution ${ }^{31}$. Based on the distribution of birdwing species/subspecies, Wallace ${ }^{1}$ was convinced that settling down (dispersal and establishment into a new island) was the main process of diversification in the region. Yet, recent studies showed that dispersal does not appear to have played a major role in avian diversification in the IAA $^{32}$. However, we found strong evidence indicating that birdwing distribution is mostly explained by founder-event speciation with Wallacea as a main source or pathway. This result seems very likely given the dispersal abilities of many species and the nature of the IAA, a complex assemblage of thousands of islands that have almost all been colonized by these butterflies ${ }^{18}$. For instance, this pattern is particularly obvious within Troides that repeatedly colonized the Lesser Sunda Islands from Greater Sunda Islands (and vice versa) in the late Miocene and Pliocene (Fig. 2). Contrary to other butterflies ${ }^{11}$, vicariance had a lower impact on diversification. Only three vicariant events were inferred, the divergences: (i) between Ornithoptera and Troides in the early Miocene, (ii) between T. hypolitus and the remaining Troides in the mid-Miocene, and (iii) between the two Trogonoptera species in the Pleistocene. The timeframe of the two first vicariant events corresponds well with the build-up of Sulawesi ${ }^{13,16}$, and the third is probably attributable to Pleistocene sea-level changes ${ }^{14}$. Biogeographical analyses further indicated multiple transgressions of Wallace's line in Troides (none in Ornithoptera), and of Lyddeker's line in Ornithoptera (one in Troides). This result suggests a higher permeability to dispersal across Wallacea. Interestingly, this pattern was also recovered in other groups of butterflies ${ }^{11,33,34}$, beetles ${ }^{12}$ and plants ${ }^{10}$. However, we did not find evidence (contrary to palms ${ }^{10}$ ) for variation in speciation and extinction rates that can be attributed to geological changes or the crossing of Wallace's and Lyddeker's lines. Founder-event speciation, likely accounted for by the strong dispersal abilities of birdwing butterflies, has probably allowed these insects to continuously colonize remote islands whenever they appeared and to establish insular radiations as Wallace predicted. For instance, Troides haliphron has reached the remote and isolated Lucipara Islands (Troides h. bellwoni).

It is often thought that a long-term stable environment leads to lower extinction and, therefore, greater biodiversity ${ }^{5}$, a hypothesis also known as the museum model of diversity. Recent work proposed that geologically dynamic regions play a major role in diversification ${ }^{15,35,36}$. In the ecosystems of the IAA, geological studies suggested that tectonic events such as the building of Sulawesi and the Philippines, as well as the orogeny of New Guinea, have caused large-scale landscape and climatic changes in the last $15 \mathrm{Myr}^{13,33}$. Alternatively, geologically dynamic regions may have destroyed previous habitats, leading to extinction (contrary to long-term stable environments). In the context of island biogeography and the IAA region, the rise and fall of sea levels through time is an important factor affecting opportunities to diversify because it creates (low sea level) or erases (high sea level) areas where radiations took place. We found evidence for higher extinction rates during warm climates and elevated sea levels. Ali and Aitchison $^{31}$ examined the impact that geological and climatic events (namely island ontogeny and shifting sea levels) had on biodiversity in the Galapagos Islands. The authors proposed that the dynamics of isolation caused by geological and climatic processes play a fundamental part in shaping diversity. Our study on birdwing butterflies and other studies on distinct groups of butterflies ${ }^{11,33,34,37}$ support this hypothesis. For instance the ancestor of Ornithoptera victoriae has likely arisen by a dispersal event from mainland New Guinea to the Solomon Islands via the Bismarck Archipelago, followed by subsequent extinctions in the Bismarck Archipelago that can possibly explain the absence of the subgenus Aetheoptera in these islands (Fig. 2). In addition, we underline the important role of extinction in this mechanism because suitable habitats were probably continuously destroyed by successive environmental changes, resulting in the likely extinction of species unable to disperse or adapt. Surviving lineages were successful dispersers able to cope and rapidly adapt to changing conditions and/or newly colonized environments.

To explain differences in birdwings' species richness at both taxonomic and biogeographical scales, we can postulate the role of ecological limits to diversification. Under this hypothesis clade diversity 
is regulated by ecological factors (species richness is independent of clade age), such as diversification rates slowing down as diversity increases because opportunities for speciation concurrently decrease. Competitive interactions between congeneric butterfly species are a strong prediction of Wallace's work ${ }^{1}$. Support for the latter hypothesis is provided by our results, which indicate that diversity-dependent processes are at play in birdwing butterflies. We found that extinction increases when diversity increases. The parallel increase of extinction and diversity is potentially explained by a decrease of population size per species as the number of species increases ${ }^{38}$. Diversity equilibrium was apparently reached faster in Sahul (for the radiation of Ornithoptera) rather than in Sunda (for the radiation of Troides) as suggested by our estimations of carrying capacities (more elevated in Sunda, Table 1). A smaller carrying capacity for Ornithoptera may explain why there are more species in Troides (with no differences in ages or time-dependent diversification rates). This finding might be rationalized by an area-size effect since Ornithoptera have only radiated in the Sahul Shelf (particularly New Guinea) and have not succeeded in colonizing the Sunda Shelf (contrary to Troides). Differences in host plants within the family Aristolochiaceae might also explain the differences in diversity because Troides feed on the genus Aristolochia, which is widespread and diverse in all of the IAA, whereas Ornithoptera feed on the subgenus Pararistolochia, with only a few species restricted to Sahul (Aristolochia plants in other subgenera can be lethal for Ornithoptera ${ }^{20}$ ).

This study also gives us the opportunity to assess whether phylogenetic inferences of past diversification dynamics may help to understand the current biodiversity crisis ${ }^{39}$. Global environmental changes that are principally due to human activities contribute to eroding biodiversity directly or indirectly, notably through the warming event we are currently experiencing. In the case of birdwings, the combination of high sea levels and high temperatures apparently led to drastic periods of extinction in the late Oligocene and in the early to mid-Miocene. If the diversification pattern that we inferred holds over macroevolutionary timescales (i.e. phylogenetic conservatism), it suggests that their current biodiversity is threatened by ongoing changes. In this case, the mid-Miocene would be an ancient analogue for current changes. However, comparing past and current effects of environmental changes on biodiversity is complicated by differences between human-driven environmental changes and long-term natural processes. Harnik et al. ${ }^{40}$ compiled information on the drivers of ancient and modern marine extinctions, and found that some drivers are shared with past and current environmental conditions, while additional pressures such as overexploitation and pollution are new threats. The two most important pressures on current biodiversity are habitat loss and climate change ${ }^{40}$. Macroevolutionary analogies to habitat loss include abrupt climatic events, sea-level increase, or major ecological transitions, which may be similar to human-driven habitat degradation and loss today. Hence, although analogies between past and present environmental changes are sometimes highly speculative, they can be relevant to making predictions on the fate of biodiversity ${ }^{40}$.

Conclusions about the nature of diversification depend upon the quality of the underlying data. Incomplete taxon sampling, poor divergence time estimations and small-sized phylogenies are potentially serious problems that are difficult to address. These can lead to inaccurate parameter estimates or wrong model selections. Such methodological limitations may constrain the certainty of our interpretations and conclusions. As long as the fundamental hypothesis testing nature of these analyses are kept in mind, they still remain our best window into understanding the rich, deep past of Earth's stupendous biological diversity. We hope that our approach will provide interesting perspectives for future investigations on other model groups with larger phylogenies. Both climate and sea-level variation, coupled with the formation of Wallacea as a biogeographical crossroads, have often been considered to be strong diversification drivers, but their combined contribution has rarely been demonstrated. We have provided insights into the effect of climatic and geological events, consistent with a pattern of spatio-temporal habitat dynamics that continuously created/erased suitable habitats. Given the prevalence of environmental fluctuations that offer temporal habitat opportunities at various timescales in nature, this result has important implications for understanding diversification patterns in many natural systems.

\section{Methods}

Taxon sampling and molecular dataset. About $90 \%$ of birdwing species were included (Supplementary Table S5). This sampling encompasses all described genera and subgenera, including 182 specimens of birdwing butterflies representing all 14 known Ornithoptera species, 17 of 21 Troides species, and the two species of Trogonoptera. Only four species (Troides darsius, T. dohertyi, T. minos and T. plateni) were not sampled. Most specimens come from museum collections and permits were obtained by the first author for species included in CITES or IUCN Red lists. Based on the most comprehensive phylogeny of Papilionidae ${ }^{41}$, we also included representatives from all remaining Troidini genera in order to implement secondary calibrations. Thirty-one species of Troidini (from Atrophaneura, Battus, Cressida, Euryades, Pachliopta and Pharmacophagus) were added to the dataset for that purpose. Three mitochondrial genes (cytochrome oxidase I, NADH dehydrogenase 5, and 16S rRNA) and two nuclear protein-coding genes (elongation factor-1a and wingless) were used. DNA sequences were either downloaded from GenBank $k^{21,23,41,42}$ or newly obtained using standard molecular protocols ${ }^{42}$. Taxon sampling and GenBank accession numbers are given in Supplementary Table S5. 
Phylogenetics and dating. Phylogenetic relationships were reconstructed under Bayesian inference (Supplementary Text S2). Gene trees were then used as a blueprint to generate a species-level dataset (with one specimen per species). Based on this reduced dataset we estimated divergence times with an uncorrelated lognormal Bayesian relaxed-clock approach. We used secondary calibrations based on a fossil-calibrated phylogeny of Papilionidae ${ }^{41}$. Uniform distributions enforced strict maximum and minimum ages based on the confidence intervals of six nodes (Supplementary Text S2).

Biogeography. The estimation of ancestral areas was carried out with the model BioGeography with Bayesian (and likelihood) Evolutionary Analysis of RangeS (BioGeoBEARS ${ }^{27}$ ). Species ranges were coded by presence-absence (excluding marginal distribution). The biogeographical model included nine component areas (see the inserted map on Fig. 2) with respect to regional palaeogeographical evidence ${ }^{13}$. While BioGeoBEARS allows building time-stratified biogeographical models with time slices representing major periods of geological rearrangements, we did not use such models because of the high geological complexity of the region. Many uncertainties, in particular regarding Halmahera, New Guinea, the Philippines and Sulawesi, remain about the appearance or disappearance of islands, and the timing of these geological events still represents a challenge ${ }^{13,15,43}$. Birdwings are also such good dispersers that they have colonized almost the entire IAA (Supplementary Text S2). Therefore the use of a subjective dispersal rate matrix was avoided for these analyses. We tested the dominant process(es) (range expansion followed by allopatry or founder-event speciation) involved in the biogeographical dynamics by comparing six distinct models including or excluding founder-event speciation and vicariance ${ }^{27}$.

Diversification rates. In order to take into account both phylogenetic and dating uncertainties, we used 500 randomly chosen trees from the BEAST post-burnin posterior distribution to estimate diversification rates with different methods. See Supplementary Text S2 for more details in each model of diversification.

We estimated the influence of Wallacea on speciation and extinction rates using the likelihood approach called Geographic State Speciation and Extinction (GeoSSE) $)^{44}$ implemented in the R package diversitree ${ }^{45}$. This likelihood-based approach allows the estimation of region-dependent rates of speciation, extinction, and range evolution from a phylogeny, using a model that combines features of constant-rates birth-death models with a three-state Markov model ${ }^{44}$. We coded each species according to its distribution using three distinct states: Wallacea, outside Wallacea or widespread. Life history data was obtained from the taxonomic literature and museum records. We constructed the likelihood functions representing 12 different evolutionary models for the relationship between geographical distributions and diversification rate. To support the Wallacean species-pump hypothesis, the best model should demonstrate a higher diversification rate for Wallacea.

We tested the hypothesis that diversification was rapid in the early stage of the group as expected under the ecological opportunities provided by the emergence of regional islands. Secondly, this diversity may have reached an equilibrium (or has been bounded), meaning that it is saturated towards the present and diversification rates slowed down. We thus explored the effect of diversity on speciation and extinction rates using the method of Etienne et al. ${ }^{29}$. We built five models: (i) speciation declines linearly with diversity and no extinction, (ii) speciation declines linearly with diversity and extinction, (iii) speciation declines exponentially with diversity and extinction, (iv) extinction increases linearly with diversity, and $(v)$ extinction increases exponentially with diversity. The initial carrying capacity was set to the current species diversity, and the final carrying capacity was estimated according to the models and relative parameters. These analyses were performed for the whole birdwing butterfly clade and the genera Ornithoptera and Troides separately.

Finally, we evaluated the impact of palaeo-environment on diversification rates using an environmental-dependence mode ${ }^{46}$. This model estimates the effect that a given environmental variable may have on diversification, by assessing whether speciation or extinction rates have a particular dependency with the variable of interest. For example, in the case of exponential dependency on temperature, a positive estimated $\alpha$ would indicate that higher temperatures enhance speciation, whereas a negative $\alpha$ would indicate that higher temperatures hamper speciation ${ }^{46}$. The impact of changes in past sea levels and palaeo-temperatures was tested using palaeo-environmental data compiled from Miller et al. ${ }^{17}$ for past sea levels and from Zachos et al. ${ }^{47}$ for palaeo-temperatures. Six models were designed for each palaeo-environmental variable to assess speciation and extinction that may vary or not as a function of changes in palaeo-temperatures or past sea levels.

\section{References}

1. Wallace, A. R. On the phenomena of variation and geographical distribution as illustrated by the Papilionidae of the Malayan region. Trans. Linn. Soc. Lond. 25, 1-71 (1865).

2. Zachos, F. E. \& Habel, J. C. Biodiversity hotspots. Distribution and protection of conservation priority areas (Springer-Verlag Berlin Heidelberg, 2011).

3. de Bruyn, M. et al. Borneo and Indochina are major evolutionary hotspots for Southeast Asian biodiversity. Syst. Biol. 63, 879-901 (2014)

4. Wallace, A. R. On the zoological geography of the Malay Archipelago. J. Proc. Linn. Soc. 4, 172-184 (1860).

5. Wallace, A. R. Tropical nature and other essays (Macmillan, 1878). 
6. Lydekker, R. A geographical history of mammals (Cambridge University Press, Cambridge, U.K., 1896).

7. Simpson, G. G. Too many lines; the limits of the oriental and Australian zoogeographic regions. Proc. Am. Philos. Soc. 121, 107-120 (1977).

8. Beck, J., Kitching, I. J. \& Linsenmar, K. E. Wallace's line revisited: has vicariance or dispersal shaped the distribution of Malesian hawkmoths (Lepidoptera: Sphingidae). Biol. J. Linn. Soc. 89, 455-469 (2006).

9. Van Welzen, P. C., Parnell, J. A. N. \& Slik, J. W. F. Wallace's line and plant distributions: Two or three phytogeographical areas and where to group Java? Biol. J. Linn. Soc. 103, 531-545 (2011).

10. Bacon, C. D. et al. Geographic and taxonomic disparities in species diversity: dispersal and diversification rates across Wallace's line. Evolution 67, 2058-2071 (2013).

11. Condamine, F. L. et al. Fine-scale biogeographical and temporal diversification processes of peacock swallowtails (Papilio subgenus Achillides) in the Indo-Australian Archipelago. Cladistics 29, 88-111 (2013).

12. Tänzler, R., Toussaint, E. F. A., Suhardjono, Y. R., Balke, M. \& Riedel, A. Multiple transgressions of Wallace's line explain diversity of flightless Trigonopterus weevils on Bali. Proc. R. Soc. Lond. B 281, 20132528 (2014).

13. Hall, R. Late Jurassic-Cenozoic reconstructions of the Indonesian region and the Indian Ocean. Tectonophys. 570, 1-41 (2012).

14. Esselstyn, J. A., Timm, R. M. \& Brown R. M. Do geological or climatic processes drive speciation in dynamic archipelagos? The tempo and mode of diversification in Southeast Asian shrews. Evolution 63, 2595-2610 (2009).

15. Toussaint, E. F. A. et al. The towering oceanic orogeny of New Guinea as a trigger of arthropod megadiversity. Nature Comm. 5, 4001 (2014).

16. Stelbrink, B., Albrecht, C., Hall, R. \& von Rintelen, R. The biogeography of Sulawesi revisited: is there evidence for a vicariant origin of taxa on Wallace's "anomalous island"? Evolution 66, 2252-2271 (2012).

17. Miller, K. G. et al. The Phanerozoic record of global sea-level change. Science 312, 1293-1298 (2005).

18. Haugum, J. \& Low, A. M. A monograph of the birdwing butterflies. The systematics of Ornithoptera, Troides and related genera (Denmark, Scandinavian Science Press, 1978-1985).

19. Zeuner, F. E. Studies in the systematics of Troides Hübner (Lepidoptera Papilionidae) and its allies: distribution and phylogeny in relation to the geological history of the Australasian Archipelago. Trans. Zool. Soc. Lond. 25, 107-184 (1943).

20. Parsons, M. J. Gondwanan evolution of the troidine swallowtails (Lep.: Pap.): cladistic reappraisals using mainly immature stage characters, with focus on the birdwings Ornithoptera Boisduval. Bull. Kitakyushu Museum Nat. Hist. 15, 43-118 (1996).

21. Morinaka, S. et al. Molecular phylogeny of birdwing butterflies based on the representatives in most genera of the tribe Troidini (Lep., Papilionidae). Entomol. Sci. 2, 347-358 (1999).

22. Matsuka, H. Natural history of birdwing butterflies (Matsuka Printing Co., Tokyo, Japan, 2001).

23. Braby, M. F., Trueman, J. W. H. \& Eastwood, R. When and where did troidine butterflies (Lepidoptera: Papilionidae) evolve? Phylogenetic and biogeographic evidence suggests an origin in remnant Gondwana in the Late Cretaceous. Invert. Syst. 19, 113-143 (2005).

24. Fordyce, J. A. The lethal plant defense paradox remains: inducible host-plant aristolochic acids and the growth and defense of the pipevine swallowtail. Entomol. Exp. Appl. 100, 339-346 (2001).

25. Mallet, J. Alfred Russel Wallace and the Darwinian species concept: his paper on the swallowtail butterflies (Papilionidae) of 1865. Gayana 73, 35-47 (2009).

26. Ronquist, F. \& Sanmartín, I. Phylogenetic methods in biogeography. Annu. Rev. Ecol. Evol. Syst. 42, 441-464 (2011)

27. Matzke, N. J. Model selection in historical biogeography reveals that founder-event speciation is a crucial process in island clades. Syst. Biol. 63, 951-970 (2014).

28. Deslisle, G. A taxonomic revision of the birdwing butterflies of paradise, genus Ornithoptera, based on the adult morphology. Lambillionea 104, 3-93 (2004).

29. Etienne, R. S. et al. Diversity-dependence brings molecular phylogenies closer to agreement with the fossil record. Proc. R. Soc. Lond. B 279, 1300-1309 (2012).

30. Vane-Wright, R. I. \& de Jong, R. The butterflies of Sulawesi: annotated checklist for a critical island fauna. Zool. Verh. Leiden 343, 3-267 (2003).

31. Ali, J. R. \& Aitchison, J. C. Exploring the combined role of eustasy and oceanic island thermal subsidence in shaping biodiversity on the Galapagos. J. Biogeogr. 41, 1227-1241 (2014).

32. Weeks, B. C. \& Claramunt, S. Dispersal has inhibited avian diversification in Australasian archipelagos. Proc. R. Soc. Lond. B 281, 20141257 (2014).

33. Müller, C. J. \& Beheregaray, L. B. Palaeo island-affinities revisited - Biogeography and systematics of the Indo-Pacific genus Cethosia Fabricius (Lepidoptera: Nymphalidae). Mol. Phylogenet. Evol. 57, 314-326 (2010).

34. Müller, C. J., Wahlberg, N. \& Beheregaray, L. B. "After Africa": the evolutionary history and systematics of the genus Charaxes Ochsenheimer (Lepidoptera: Nymphalidae) in the Indo-Pacific region. Biol. J. Linn. Soc. 100, 457-481 (2010).

35. Hoorn, C., Mosbrugger, V., Mulch, A. \& Antonelli, A. Biodiversity from mountain building. Nature Geosci. 6, 154 (2013).

36. Tan, J., Kelly, C. K. \& Jiang, L. Temporal niche promotes biodiversity during adaptive radiation. Nature Comm. 4, 2102 (2013).

37. Lewis, D. L. et al. Role of Caribbean Islands in the diversification and biogeography of Neotropical Heraclides swallowtails. Cladistics 31, 291-314 (2015).

38. Wallace, A. R. Island life (New York: Harper \& Brothers, 1881).

39. Hadly, E. A. \& Barnosky, A. D. [Vertebrate fossils and the future of conservation biology]. Conservation Paleobiology: Using the Past to Manage for the Future [Dietl, G. P. \& Flessa, K. W. (eds)] [39-59] (The Paleontological Society Papers, 2009).

40. Harnik, P. G. et al. Extinctions in ancient and modern seas. Trends Ecol. Evol. 27, 608-617 (2012).

41. Condamine, F. L., Sperling, F. A., Wahlberg, N., Rasplus, J. Y. \& Kergoat, G. J. What causes latitudinal gradients in species diversity? Evolutionary processes and ecological constraints on swallowtail biodiversity. Ecol. Lett. 15, 267-277 (2012).

42. Simonsen, T. J. et al. Phylogenetics and divergence times of Papilioninae (Lepidoptera) with special reference to the enigmatic genera Teinopalpus and Meandrusa. Cladistics 27, 113-137 (2011).

43. Baldwin, S. L., Fitzgerald, P. G. \& Webb, L. E. Tectonics of the New Guinea region. Annu. Rev. Earth Planet. Sci. 40, 495-520 (2012).

44. Goldberg, E. E., Lancaster, L. T. \& Ree, R. H. Phylogenetic inference of reciprocal effects between geographic range evolution and diversification. Syst. Biol. 60, 451-465 (2011).

45. FitzJohn, R. G. Diversitree: comparative phylogenetic analyses of diversification in R. Methods Ecol. Evol. 3, 1084-1092 (2012).

46. Condamine, F. L., Rolland, J. \& Morlon, H. Macroevolutionary perspectives to environmental change. Ecol. Lett. 16, 72-75 (2013).

47. Zachos, J. C., Dickens, G. R. \& Zeebe, R. E. An early Cenozoic perspective on greenhouse warming and carbon-cycle dynamics. Nature 451, 279-283 (2008). 


\section{Acknowledgements}

We are grateful to Donald Lafontaine for providing biological material from birdwings intercepted at Canadian borders. We also want to thank Björn Stelbrink, Nick Matzke and Bernard Platevoet for earlier comments on the study. Financial support was provided by a Marie Curie International Outgoing Fellowship (project 627684 BIOMME) to FLC, an NSERC Discovery Grant to FAHS, and the Department 'Santé des Plantes et Environnement' of the Institut National de la Recherche Agronomique (INRA, SPE) to GJK.

\section{Author Contributions}

F.L.C., E.F.A.T., F.A.H.S. and G.J.K. designed the research and wrote the paper; A.L.C., G.G. and F.L.C. assembled the data sets; F.L.C. analysed the data.

\section{Additional Information}

Supplementary information accompanies this paper at http://www.nature.com/srep

Competing financial interests: The authors declare no competing financial interests.

How to cite this article: Condamine, F. L. et al. Deciphering the evolution of birdwing butterflies 150 years after Alfred Russel Wallace. Sci. Rep. 5, 11860; doi: 10.1038/srep11860 (2015).

(c) (i) This work is licensed under a Creative Commons Attribution 4.0 International License. The images or other third party material in this article are included in the article's Creative Commons license, unless indicated otherwise in the credit line; if the material is not included under the Creative Commons license, users will need to obtain permission from the license holder to reproduce the material. To view a copy of this license, visit http://creativecommons.org/licenses/by/4.0/ 